\title{
Relational Learning in Glaucous-Winged Gulls (Larus glaucescens)
}

\author{
Tatyana A. Obozova, Anna A. Smirnova, and Zoya A. Zorina \\ M.V. Lomonosov Moscow State University (Russia)
}

\begin{abstract}
An experimental approach was created for the comparative investigation of the cognitive abilities of the glaucouswinged gull (Larus glaucescens) in their natural habitat. The territoriality of gulls during the breeding period and the fact that the gulls inhabiting the territory of the Komandorsky Reserve are practically not in fear of humans allowed us to work with individually recognized birds directly at their nest sites inside the colony. The possibility of using this approach to investigate their cognitive abilities was demonstrated on 24 gulls, in particular, to investigate their abilities for relative size generalization. The first experiment illustrated that the gulls are able to learn to discriminate two pairs of stimuli according to the feature: 'larger' or 'smaller'. They were then given a test to transfer the discriminative rule in which novel combinations of the same stimuli were used. The gulls successfully coped with only a few of these tests. In the next experiment the birds were taught to discriminate four pairs of similar stimuli. The majority of the birds coped with the tests to transfer the discriminative rule both to the novel combinations of familiar stimuli, and also to the novel stimuli of the familiar category (items of different colour and shape). However, none of the birds transferred the discriminative rule to stimuli of a novel category (sets differing by number of components). Thus, in their ability to generalize at a preconceptual level gulls are more comparable with pigeons, whereas large-brained birds (crows and parrots), are capable of concept formation.

Keywords: glaucous-winged gulls, (Larus glaucescens), relational learning, generalization, concept formation.
\end{abstract}

Se empleó un enfoque experimental creado para la investigación comparativa de las habilidades cognitivas de los Larus glaucescens en su hábitat natural. La territorialidad de esta especie durante el periodo de reproducción, y el hecho de que las gaviotas que habitan el Parque natural de Komandorski no temen prácticamente al hombre, ha permitido trabajar con ejemplares individuales (concretos) directamente en sus lugares de anidamiento dentro de la colonia. Se ha demostrado sobre 24 gaviotas la posibilidad de empleo de dicho enfoque para la investigación de sus habilidades cognitivas, en concreto, para la investigación de su habilidad de generalización según el atributo relativo del tamaño. En el primer experimento se esclareció que las gaviotas son capaces de aprender a diferenciar dos pares de estímulos según sus atributos de "más" (un grupo de pájaros) y "menos" (segundo grupo de pájaros). Después se les presentaron pruebas para la transferencia de la regla de selección, en las cuales se empleaban nuevas combinaciones de los mismos estímulos. Las gaviotas realizaron de forma exitosa sólo con algunas de estas pruebas. En el siguiente experimento aprendían a diferenciar cuatro pares de estímulos análogos. La mayoría de los pájaros fueron exitosos tanto en las pruebas de transferencia de la regla de selección de nuevas combinaciones de estímulos conocidos, como de estímulos nuevos de la misma categoría (objetos de otro color y forma). Sin embargo, ni un pájaro fue capaz de transferir la regla de selección sobre estímulos de otra categoría (cantidades que difieren en el número de componentes). Así, en cuanto a las habilidades de generalización a un nivel pre-conceptual, las gaviotas son comparables más bien con palomas, ya que pájaros con una organización superior, como son los cuervos o loros, son capaces de formar conceptos.

Palabras clave: gaviota de alas hiperbóreas, (Larus glaucescens), aprendizaje relacional, generalización, formación de concepto.

Correspondence concerning this article should be addressed to Tatyana Obozova. Department of Higher Nervous Activity, Lomonosov Moscow State University, 119899, Vorob'evy gory, 1-12, Moscow (Russia). E-mail: obozovat@mail.ru 
Investigation of a wide range of species with different levels of brain complexity and different habitats aids a deeper understanding of the nature of animals' cognitive abilities. A narrow range of standard species (mice, rats, pigeons, etc.) are usually used in laboratory experiments. Pigeons are usually used as a universal subject model to assess birds' cognitive abilities, despite the fact that they have a relatively primitive brain structure (Portmann, 1947). Representatives of other families (for example, crows and parrots) are incommensurately more seldom the subjects of such investigations, although such data significantly extends our perceptions of the cognitive abilities of birds. For example, they demonstrate how birds with different levels of brain complexity radically differ in their ability to solve cognitive tests (Zorina \& Smirnova, 2008).

To obtain comparative data it is possible not only to increase the number of species investigated in experiments under laboratory conditions, but also to transfer standard laboratory methods to the field and to conduct experiments with animals in their natural habitat (Firsov, 1977; Henderson, Hurly, \& Healy, 2006). Precisely such an attempt was undertaken in the given work.

One of the difficulties in field investigations is to create the possibility of working with individually recognized animals that are tolerant of the close proximity of humans. In the given case the glaucous-winged gull was a successful subject. There is a large colony of these birds on Toporkov Island in the Komandorsky Archipelago (Komandorsky State Natural Biosphere Reserve, Russia). The birds in this conservation territory pay no attention to the presence of humans, even up to their nests. During the breeding season each pair of gulls in the colony occupies its own small nesting site which is jealously guarded. Moreover, in each nesting site it is the male that clearly dominates; he is always the first to approach food. This enables working with individually recognized birds directly in their nesting sites without resorting to capturing them for marking.

It is known that it is typical for gulls to have highly adaptive behavior that allows them quickly to adapt to changing environmental conditions (Zelenskaya, 2003, 2008). They adopt different types of habitats, and use practically any accessible food for nutrition, which they obtain by various means (Zelenskaya, 2003, 2008; Rezanov, 2000). In their behavior gulls are in many respects similar to hooded crows, birds with complex, highly plastic behavior (Konstantinov, 1992) and a highly-organized brain (with a Portmann Hemisphere Index of 14.991) (Portmann, 1947), that are able to solve the most complicated cognitive tasks in experiments under laboratory conditions (Zorina \& Smirnova, 1995; 2008; Smirnova, Lazareva, \& Zorina, $1998 ; 2002)$. We were unable to uncover data on gulls' cognitive abilities, as also on the level of their brain organization. It is known only that the value of the Portman Hemisphere Index for representatives of the Laridae family is 4.93 , which slightly surpasses that for pigeons (3.45). In the given work we present the results of the first stage of our comprehensive investigations into the cognitive abilities of these birds: an assessment of the level of their ability to generalize the relative features of 'larger' and 'smaller'.

Generalization is the conceptual separation of general properties unifying a number of stimuli or events (Zentall et al., 2008). Generalization and abstraction (identifying differing unessential features and abstracting from them) are two inseparable parts of a single process, the result of which may be conceptualization. Two basic levels of generalization are identified: the preconceptual level (manifested in the ability reliably to transfer discriminative responses to novel stimuli of a familiar category) and the conceptual level (manifested in the ability reliably to transfer a discriminative response to novel stimuli in novel categories).

The preconceptual level of generalization is a universal ability, discovered to some extent in the majority of species (Zentall et al., 2008), whereas conceptualization is far from attainable for all animals.

It has been shown that many animals, including birds, are able to generalize according to the relative features 'larger/smaller', 'higher/lower', 'similar/different', and so on (Zentall et al., 2008). Two main methods have been used to investigate the abilities of animals to generalize relative features: animals were taught either stimuli discrimination (Lazarevaet al., 2008; Lombardi, 2008; Zorina \& Smirnova, 1995), or matching-to-sample procedures (Zorina \& Smirnova, 1995; Smirnova et al., 2002). It is the first method that was used to study the gulls' ability to generalize the relative feature of size ('larger', 'smaller') in their natural habitat.

The purpose of the given work was to develop an experimental approach enabling the investigation of the glaucous-winged gulls' cognitive abilities in their natural habitat, and to discover to what extent the gulls are capable of generalizing the relative features 'larger' and 'smaller'.

\section{Experiment 1}

\section{Method}

\section{Subjets}

Twenty-two adult males of the glaucous-winged gull species (Larus glaucescens) participated in the experiments. Judging by the colour of their plumage, they were sexually

1 The Portmann Hemisphere Index is at the moment the only universal indicator of the level of brain complexity in different species of birds. 
mature individuals whose age was no less than 5 years (Yudin \& Firsova, 2002).

The study was conducted from the beginning of June until the end of July (during the gulls' breeding period) in 2008-2009 on Toporkov Island, one of the small islands in the Komandorsky Archipelago (Komandorsky State Natural Biosphere Reserve, Russia), where each pair occupied and protected its own small nesting site.

Only the male in each nesting site participated in the experiments. Individual identification was carried out according to the birds' association with an actual nesting site and by the male's behavior during feeding (he always would dominate the female).

Experiments were conducted from 9 o'clock in the morning until 9 o'clock at night.

\section{Apparatus}

Four blue cardboard boxes without lids and of different sizes were used as stimuli: $5 \times 5 \times 5 \mathrm{~cm}$ (stimulus No.1), $10 \times 10 \times 10 \mathrm{~cm}$ (stimulus No.3), $20 \times 20 \times 20 \mathrm{~cm}$ (stimulus No.4), and $40 \times 40 \times 40 \mathrm{~cm}$ (stimulus No.6); the lateral area of each subsequent box was four times larger than the lateral area of the previous one.

\section{Procedure}

The training was carried out using two pairs of stimuli: 1 and $3 ; 4$ and 6. Pairs of stimuli were alternated in quasirandom fashion: in 8 presentations one pair was used 4 times and the other 4 times, with each pair of stimuli presented no more than twice in succession.

One group of 8 gulls was trained to select the largest box from each pair (the 'larger' group'), and the other group of 8 gulls - the smaller box (the 'smaller' group).

The stimuli (boxes) were placed on wooden stands $40 \mathrm{~cm}$ in height so that the gull was unable to see the box's contents. The stands were set at a distance of one metre from each other.

The relative arrangement of previously reinforced and previously non-reinforced stimuli was varied in quasirandom fashion (in 8 successive presentations, 4 times on the left and 4 times on the right; no more than twice in succession on either side).

The training commenced with teaching the birds to retrieve feed from the box. To do this the experimenter would place a box on each stand (the same two pairs of stimuli were used as in the main training). Then in front of the birds the experimenter would place some bait - a piece of fish - in the box. If the bird did not show any interest in the bait concealed in the box, the experimenter would perform an additional demonstration: he would take the bait and place it on the edge of the box so that it was visible to the bird. Subsequent presentations were carried out similarly to the first time until the bird itself retrieved the feed without the additional demonstration.
After this, the training continued without demonstrating the feed's presence in one of the boxes. Out of sight of the bird (behind a screen), the experimenter would place a reinforcement - a piece of fish - in one of the two boxes. He would then approach the stands and simultaneously place a box on each of them, after which he would retire to a distance of no less than five metres. The bird would make its selection by jumping on a box or by dragging it off the stand with its beak. If the selection was correct, the experimenter would remove the boxes and begin to prepare a novel pair of stimuli. If the selection was incorrect, the bird was given the opportunity to select the other box. Only the result of the first selection was recorded for each presentation.

The training was conducted until a criterion was achieved of no less than 8 correct decisions per 10 successive presentations (with no less than 4 correct decisions per 5 presentations of each of the two pairs of stimuli).

In the final test each gull was presented once with four novel combinations of earlier used stimuli: 1 and $4 ; 3$ and $6 ; 3$ and $4 ; 1$ and 6 . Reinforcement was placed in both boxes. In the two novel pairs ( 1 and 4; 3 and 6) the stimuli had an identical signal value, that is, both had always been previously reinforced or both had always not been reinforced. In the other two pairs (3 and 4; 1 and 6) the stimuli had a different signal value. That is, one of them had always been previously reinforced, and the other not. Also, in one pair the 'correct' stimulus was always previously reinforced, and in the other - not.

The confidence level of the correct decisions was assessed according to a binomial test.

\section{Results}

\section{Training}

To achieve the training criterion, birds from both groups required from 12 to 51 presentations. Birds trained to choose the larger stimulus required from 12 to 48 presentations to achieve the criterion; birds trained to select the smaller stimulus-from 16 to 51 presentations. No differences in the training dynamics for the birds were detected.

\section{Test}

When presenting a pair consisting of previously reinforced stimuli (pairs of stimuli 3 and 6 for the 'larger' group, and 1 and 4 for the 'smaller' group), seven of the eight birds from the 'larger' group and six birds from the 'smaller' group successfully coped with the test (Fig. 1). This signifies that the birds not only remembered two positively reinforced objects, but also identified the relative features of 'larger' and 'smaller'. 


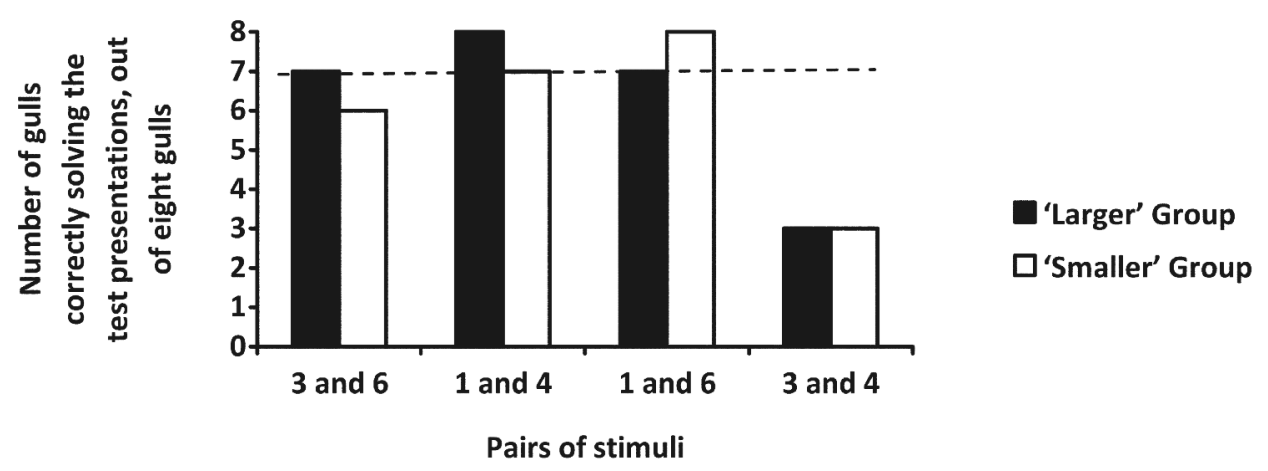

Figure 1. Results of Experiment 1: Number of gulls correctly solving the test presentations, out of eight gulls. Note: The dotted line indicates the statistical threshold (binomial test).

When the correct decision was the selection of a previously reinforced stimulus (pair of stimuli 1 and 6 for both groups), seven of eight birds in the 'larger' group and all eight birds in the 'smaller' group coped with the test (Fig. 1). When the correct decision was the selection of a previously non-reinforced stimulus (pair of stimuli 3 and 4 for both groups), only three of the eight birds in both groups coped with the test, the remaining five birds in each group continuing to select the previously reinforced stimuli (Fig. 1). Thus, information on the reinforcement and positively reinforced objects remained more significant for the birds than the generalization of information on their relative sizes.

In order to assess the extent to which the gulls were capable of generalizing the discriminative rule formed regarding the relative features of 'larger/smaller', Experiment 2 was conducted in which not two, but four pairs of stimuli were used in the training. In this way the birds received more information to identify and generalize the relative features. Stimuli of the same category were used in the transfer tests: novel colours and shape, and another category: sets differing by number of components.

\section{Experiment 2}

\section{Subjects}

\section{Method}

A detailed description of the site and place of the investigation is given in the Methods for Experiment 1.

\section{Apparatus}

Six brown cardboard boxes of different sizes were use as stimuli in the training. The sizes (length/height/width) of the boxes were: $5 \times 5 \times 5 \mathrm{~cm}$ (stimulus No. 1 ), $7.5 \times 7.5 \times 7.5$ $\mathrm{cm}$ (stimulus No. 2), $10 \times 10 \times 10 \mathrm{~cm}$ (stimulus No. 3), $20 \times 20 \times 20 \mathrm{~cm}$ (stimulus No. 4), $30 \times 30 \times 30 \mathrm{~cm}$ (stimulus No. 5), and $40 \times 40 \times 40 \mathrm{~cm}$ (stimulus No. 6).
Six differently-coloured cardboard boxes were uses as stimuli in Test 2: three red boxes and three blue boxes. The shape and sizes of the test stimuli matched the shape and sizes of the stimuli used during the training.

Six differently-coloured buckets were used in Test 3 as stimuli with a novel shape. The sizes of the test stimuli approximately matched the sizes of the stimuli used during the training.

As stimuli of a novel category (number of items) in test 4, pairs of sets consisting of 2 and 3;2 and 4;2 and 5; 3 and 4 ; and 3 and 5 small cubes were used. In all, eight plastic cubes of different colours were used: 2 yellow, 2 green, 2 red and 2 blue, but all of identical size: $7 \times 7 \mathrm{~cm}$. The sets of cubes were placed on the stands so that they were no less than $2 \mathrm{~cm}$ apart and looked like individual pieces. During secondary use of a pair of sets, the colour makeup of the constituent elements was changed. In each set there was always one red cube in which the feed was contained.

\section{Procedure}

The training procedure is described in detail in Experiment 1. A group made up of 5 gulls was trained to select the largest of a pair of stimuli (the 'larger' group). Another group, made up of three gulls, was trained to select the smallest of a pair of stimuli (the 'smaller' group). Training was carried out on four pairs of stimuli: 1 and 3, 4 and 6, 1 and 6 , and 2 and 5 .

In order to reveal if the gulls were able to relinquish the signal value of the stimuli after training on 4 pairs of stimuli, in Test 1, as also in the test in Experiment 1, two novel pairs of stimuli were presented, consisting of stimuli with an identical signal value during initial training (both were reinforced or both were non-reinforced, Test 1a) and two novel pairs, consisting of stimuli with different signal values (one stimulus previously reinforced, the other not, Test 1b).

In order to assess the degree of generalization in the discriminative rule formed as a result of the training, transfer tests were performed: novel stimuli of the same category, 
unused during the training, were presented: in Test $2-$ stimuli with a novel colour, in Test 3 - stimuli with a novel shape and novel colour. In Test 4 stimuli of a novel category were used - arrays of cubes. If the proportion of correct decisions in Tests 1-4 did not exceed the random level, after the test a series of presentations of stimuli used during training was performed in order to confirm that the bird had not forgotten the discriminative rule. Reinforcement was placed in both boxes. The arrangement of the stimuli was varied in a quasi-random manner.

\section{Results}

\section{Training}

To achieve the training criterion (no less than 16 correct selections per 20 successive presentations of stimuli), birds from both groups required from 21 to 68 presentations. Birds trained to select the larger stimulus required from 21 to 49 presentations to achieve the criterion; birds trained to select the smaller stimulus - from 28 to 68 presentations.

No differences in the training dynamics for the birds in the two groups were detected.
Tests

Test 1 - Presentation of stimuli previously having identical and different signal values

When presenting stimuli previously having an identical signal value (pairs of stimuli 1 and 4; 3 and 6), four birds in the 'larger' group and all the birds in the 'smaller' group successfully made the selection (Fig. 2a and $2 b$ ). The results of this test confirmed the results obtained in Test 1 of the first experiment.

When the correct decision was the selection of a previously non-reinforced stimulus (in stimuli pairs 3 and 4), two of the five birds in the 'larger' group and two of the three birds in the 'smaller' group responded properly. The remaining three birds in the 'larger' group and one bird in the 'smaller' group made selections at a random level (Fig. $2 \mathrm{a}$ and $2 \mathrm{~b}$ ). Thus, when increasing the number of stimuli used during the training, information on reinforcement and the positively reinforced stimuli becomes less significant than information on the correlation of their relative size.

\section{Test 2 - Presentation of stimuli with a novel colour}

One of the three birds tested in the 'larger' group and both birds tested in the 'smaller' group made selections

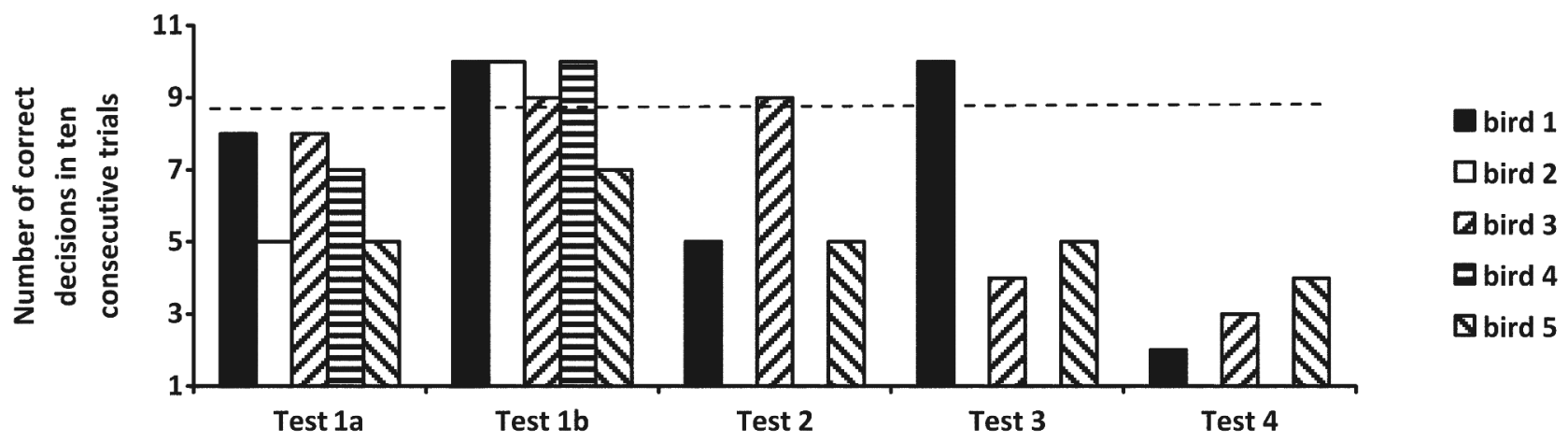

Figure 2a. Results of Experiment 2: Number of correct decisions of gulls in the 'larger' group, in ten consecutive presentations of stimuli in tests $1-4$.

Note: The dotted line indicates the statistical threshold (binomial test).

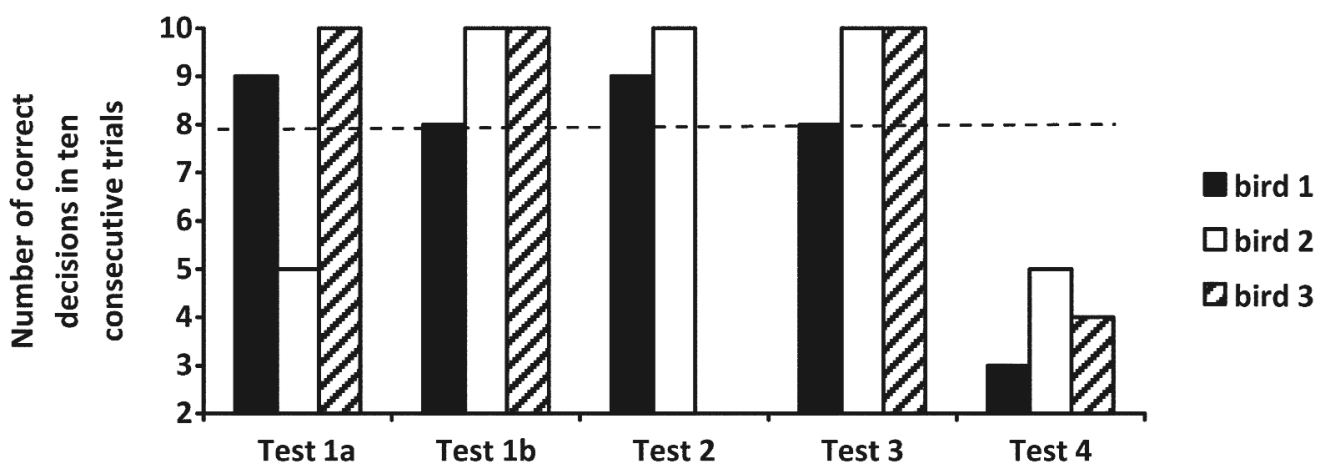

Figure 2b. Results of Experiment 2: Number of correct decisions of gulls in the 'smaller' group, in ten consecutive presentations of stimuli in tests 1-4.

Note: The dotted line indicates the statistical threshold (binomial test). 
successfully (Fig. 2a and 2b). The proportion of correct decisions for two birds in the 'larger' group did not exceed the random level (Fig. 2a). This signifies that after training for four differentials, only certain gulls were able to transfer the discriminative rule to stimuli of a novel colour not used during the training.

\section{Test 3 - Presentation of stimuli of the familiar category} with a novel shape and colour

One of the three birds tested in the 'larger' group and all three birds in the 'smaller' group solved this transfer test successfully (Fig. 2a and 2b). The proportion of correct decisions for two birds in the 'larger' group did not exceed the random level (Fig. 2a). This signifies that after training for four differentials, certain gulls were able to transfer the discriminative rule to stimuli of a novel colour and shape.

\section{Test 4 - Presentation of pairs of sets (stimuli of a novel} category)

Not a single bird from either group coped with the test 4 (Fig. 2a and 2b). This signifies that after training for four discriminative pairs, the gulls were unable to transfer the discriminative rule to stimuli of novel category.

\section{Discussion}

An experimental approach was developed and tested that allowed the glaucous-winged gulls' cognitive abilities to be studied in their natural habitat. Using this approach it was shown that the glaucous-winged gulls are able to generalize the relative features of 'larger' and 'smaller'. This confirms the notion that the ability to generalize (a basic cognitive operation) is a universal ability inherent among the representatives of different, including evolutionary ancient, taxonomic groups of animals (Lazareva et al., 2008; Lombardi, 2008).

In order to assess the level of generalization possessed by the gulls concerning the relative features we used two types of transfer tests: transfer to novel stimuli of the same category and transfer to novel stimuli of novel category (Wilson et al., 1985). The ability to transfer to stimuli of the same category (insignificantly differing from those used during training) is shown not only for large-brained representatives of a class of birds - crows and parrots (Koehler, 1956; Pepperberg, 1987, 2000; Wilson et al., 1985), but also for pigeons - birds with a low level of brain structure that have a Portmann Index (Portmann, 1947) the same as gulls, approximately corresponding to a four (Emery, 2006; Lazareva et al., 2008; Zentall et al., 2008; Wright \& Delius, 2005). For example, pigeons trained to select coloured boxes by similarity, in the transfer tests successfully selected novel stimuli not used during the training (Katz \& Wright, 2006). In our experiments gulls from both groups ('larger' and 'smaller') in the transfer tests successfully selected correct stimuli that had a novel colour and shape (Experiment 2, Tests 2 and 3, Fig. 2a and $2 b)$. Consequently, the transfer of the discriminative rule to stimuli of the same category did not present any difficulty for these birds.

The majority of animal species cannot cope with the transfer of a discriminative rule to stimuli of novel category that differ radically from those used during training (Zentall et al., 2008). For example, pigeons trained to select by similarity of colour were not able correctly to establish the similarity by type of hatching and this task had to be relearned (Wilson et al., 1985). As the only exception, Lombardi's work should be mentioned in which a special non-standard methodology was used and several pigeons trained to select stimuli according to similarity of colour were able correctly to establish similarity by shape (Lombardi, 2008). Representatives of the Corvidae family - birds with a large and finely differentiated brain that have a Portmann Index approximately corresponding to 16 (Portmann, 1947), were able to transfer a discriminative rule to another category of stimuli (Zorina \& Smirnova, 2008; Wilson et al., 1985; Koehler, 1956). For example, jackdaws trained to select by shape similarity of differently coloured stimuli, in the transfer test selected similar stimuli with different types of hatching (Wilson et al., 1985). Distinct from large-brained Corvidae, gulls in our experiments, as also pigeons, could not cope with transferring a discriminative rule to a novel category of stimulus: sets, differing by number of elements (Experiment 2, Test 4, Fig. 2a and ab). However, this test is highly complex as testified to by the fact that even hooded crows and young orange-winged amazons (unpublished data) could not always make the transfer to stimuli in a novel category. Thus, in the experiments of Smirnova and the co-authors, hooded crows successfully having mastered the rule for selecting stimuli by similarity of colour, only after additional training were able accurately to select stimuli by similarity of shape in two novel categories: Arabic numbers and sets differing by number of items (Smirnova et al., 1998).

It is important to note that the degree of generalization of the discriminative rule strongly depends on the specifics of the training procedure (Lombardi, 2008) and the number of stimuli used in the training (Bodily et al., 2008, Lazareva et al., 2008). 1). These data coincide with the results obtained for pigeons (Marsh, G., 1967) and hooded crows (unpublished data). However, after training for four pairs of stimuli, the birds much more successfully solved tests with novel combinations of stimuli used during the training (Experiments 1 and 2, Test 1, Fig. 1, 2a and 2b), than after training for two pairs of stimuli. Similar results were obtained previously in experiments on pigeons (Lazareva et al., 2008). Only those birds whose training was conducted with the use of two and three pairs of stimuli coped with the transfer test when the correct choice was a previously non-reinforced stimulus. The level of correct decisions for pigeons whose 
training was conducted with one pair of stimuli did not exceed the random level (Lazareva et al., 2008).

As the results of Tests 2-4 showed, gulls were capable of a low level of generalization concerning 'larger' and 'smaller': they were able to transfer the discriminative rule only to stimuli of the familiar category (insignificantly differing from those that were used for the training). In this they did not differ from pigeons which have a similar level of cerebral development (judging by their Portmann Index value).

The development level of generalization ability is an objective measure of the development level of animals' intelligence. This permits the assumption that the gulls' very plastic behavior in nature is mediated by other mechanisms unassociated with these birds' intelligence.

This work is a field experiment investigating the cognitive abilities of gulls in their natural habitat. The approach we developed permits the range of this species' cognitive capabilities to be comprehensively described with the use also of other laboratory methods.

\section{References}

Bodily, K. D., Katz, J. S., \& Wright, A. A. (2008). Matching-tosample abstract-concept learning by pigeons. Journal of Experimental Psychology: Animal Behavior Processes, 34, 178-184. http://dx.doi.org/10.1037/0097-7403.34.1.178

Emery, N. J. (2006). Cognitive ornithology: The evolution of avian intelligence. Philosophical Transactions, 361, 23-43. http://dx.doi.org/10.1098/rstb.2005.1736

Firsov, L. A. (1977). Povedenie antropoidov v prirodnykh usloviakh. [Behavior of anthropoids under natural conditions]. Leningrade, Russia: Nauka.

Henderson, J., Hurly, T. A., \& Healy, S. D. (2006). Spatial relational learning in rufus hummingbirds (Selasphorus rufus). Animal Cognition, 9(3), 201-205. http://dx.doi.org/10.1007/s10071006-0021-z

Katz, J. S., \& Wright, A. A. (2006). Same/different abstract concept learning by pigeons. Journal of Experimental Psychology: Animal Behavior Processes, 32(1), 80-86. http://dx.doi.org/10.1037/0097-7403.32.1.80

Koehler, O. (1956, October). Thinking without words. Proceedings of the $14^{\text {th }}$ International Congress of Zoology (pp. 75-88). Copenhagen, Denmark.

Konstantinov, V. M. (1992): Fauna, naselenie i ekologia ptits antropogennych landshaftov lesnoy zony Russkoi ravniny: Problemy sinantopizatsii $i$ urbanizatsii ptits. [Fauna, bird population and ecology in anthropogenic landscapes of the forest zone on the Russian plain: Problems of bird synantropization and urbanization]. (Doctoral dissertation). Moscow, Russia.

Lazareva, O. F., Miner, M., Wasserman, E. A., \& Yuong, M. E. (2008). Multiple - pair training enhances transposition in pigeon. Learning and Behavior, 36(3), 174-187. http://dx.doi.org/10.3758/LB.36.3.174
Lombardi, C. M. (2008). Matching and oddity relational learning by pigeons (Columbia livia): Transfer from colour to shape. Animal Cognition, 11, 67-74.

Marsh, G. (1967). Relational learning in the pigeon. Journal of Comparative and Physiological Psychology, 64(3), 519-521. http://dx.doi.org/10.1037/h0025210

Pepperberg, I. M. (1987). Acquisition of the same/different concept by an African Grey parrot (Psittacus erithacus): Learning with respect to categories of color, shape, and material. Animal Learning and Behavior, 15, 423-432. http://dx.doi.org/10.3758/BF03205051

Pepperberg, I. M. (2000). The Alex studies: Cognitive and communicative abilities of grey parrots. Harvard, MA: Harvard University Press.

Portmann, A. (1947). Étude sur la cérébralisation des oiseaux I. [Studies of encephalization in birds I]. Alauda, 14, 2-20.

Rezanov, A. G. (2000). Kormovoye povedenie ptits: Metod tsifrovogo kodirovania $i$ analiz bazy dannykh. [Feeding Behavior of Birds: Digital Coding Method and Analysis of Database]. Moscow, Russia: Shkola Publishing House.

Smirnova, A. A., Lazareva, O. F., \& Zorina, Z. A. (1998): Obuchenie serykh voron (Corvus cornix L.) otvlechennomu pravilu vybora po sootvetstviu/nesootvetstiviu s obraztsom. [Training hooded vrows (Corvus cornix L.) in an abstract selection rule relating to conformity/non-conformity to a sample]. Zhurnal Vyshey Nervnoy Deiatelnosti, 48, 855-867.

Smirnova, A. A., Lazareva, O. F., \& Zorina, Z. A. (2000). Use of number by crows: Investigation by matching and oddity learning. Journal of the Experimental Analysis of Behavior, 73, 163-176. http://dx.doi.org/10.1901/jeab.2000.73-163

Smirnova, A. A., Lazareva, O. F., \& Zorina, Z. A.(2002). Issledovanie sposobnosti serykh voron $\mathrm{k}$ elementam simvolizatsii. [Study of the elementary symbolization abilities of hooded crows]. Zhurnal Vyshey Nervnoy Deiatelnosti, 52(2), 241-254.

Yudin, K. A., \& Firsova, L. V. (2002). Fauna Rossii i sopredelnykh stran. Ptitsy. Vol. II. [Fauna of Russia and adjoining countries. Birds. Vol. II]. Saint Petersburg, Russia: Nauka,.

Wilson, B. J., Mackintosh, N. J., \& Boakes, R. A. (1985). Transfer of relational rules in matching and oddity learning by pigeon and corvids. Quarterly Journal of Experimental Psychology, 37, 313-332.

Wright A. A., \& Delius J. D. (2005). Learning processes in matching and oddity: The oddity preference effect and sample reinforcement. Journal of Experimental Psychology: Animal Behavior Processes, 31, 425-432. http://dx.doi.org/10.1037/00977403.31.4.425

Zelenskaya, L. A. (2003). Strategii pitania komandorskoy populatsii serokrylykh chaek (Larus glaucescens Naumann). [Feeding strategy of the Komandorsky islands glaucous-winged gull population]. Zoologicheskiy Zhurnal, 82(6), 694-707.

Zelenskaya, L. A. (2008). Izmenenye pitania gnezdiaschikhsa serokrylykh chaek Larus glaucescens na Komandorskih ostrovakh. Biologia i okhrana ptits Kamchatki. [Changes in the feeding of nesting glaucous-winged gulls (Larus glaucescens) on the Komandorsky islands. Bird biology and conservation on Kamchatka]. Moscow, Russia: Tsentr okhrany dikoy prirody. 
Zentall, T. R., Wasserman, E. A., Lazareva, O. F.,Thompson, R. K. R., \& Rattermann, M. J. (2008). Concept learning in animals. Comparative Cognition and Behavior Reviews, 3, 13-45. http://dx.doi.org/10.3819/ccbr.2008.30002

Zorina, Z. A., \& Smirnova, A. A. (1995). Kolichestvennye otsenki u serykh voron: Obobschenie po otnositelnomu priznaku "bolshee mnozhestvo". [Quantitative evaluation by of Hooded crows: Generalization by relative feature of 'larger set']. Zhurnal Vyshey Nervnoy Deiatelnosti, 45(3), 490-497.

Zorina, Z. A., \& Poletaeva, I. I. (2003). Zoopsikhologia: Elementarnoie myshlenie zhivotnykh. Uchebnoie posobie.
[Animal psychology. Elementary thought processes of animals. Textbook]. Moscow, Russia: Aspekt - Press.

Zorina, Z. A., \& Smirnova, A. A. (2008). Obobschenie, umozakliuchenie po analogii i drugie kognitivnye sposobnosti vranovykh ptits. [Generalization, reasoning by analogy and other cognitive abilities of the crow family.] Kognitivnye Issledovania, 2, 148-165.

Received March 26, 2011

Revision received September 2, 2011

Accepted September 7, 2011 